Tom Kai Ming Wang, MBCHB, MD(res), FRACP

Advanced Cardiac Imaging Fellow, Section of Cardiovascular Imaging,

Heart, Vascular, and Thoracic Institute, Cleveland Clinic
Milind Y. Desai, MD

Staff Cardiologist, Section of Cardiovascular Imaging and

Medical Director, Aorta Center, Heart, Vascular, and Thoracic

Institute, Cleveland Clinic; Professor, Cleveland Clinic Lerner

College of Medicine of Case Western Reserve University,

Cleveland, $\mathrm{OH}$

\title{
Thoracic aortic aneurysm: Optimal surveillance and treatment
}

\section{ABSTRACT}

Aneurysm of the thoracic aorta is less common than in the abdominal aorta, but it is clinically important because of the risk of rupture and death. Cases are often found incidentally. Indications for surgical or endovascular repair are based on aneurysm location and risk factors for rupture such as aneurysm size, rate of growth, and associated conditions, while medical management is also important. Surveillance with various imaging tests is critical before and after intervention to guide treatment.

\section{KEY POINTS}

Patients with bicuspid aortic valve or genetic syndromes such as Marfan syndrome are at higher risk, with lower thresholds for surgical intervention, but account for only a minority of cases.

Although echocardiography has some roles in screening and monitoring the aortic root and ascending aorta, computed tomography and magnetic resonance imaging are necessary for the complete assessment of the thoracic aorta and are often necessary for surveillance.

Guidelines from several professional societies are available regarding surveillance and indications for intervention.

Patients with thoracic aortic aneurysm require multidisciplinary care, including a cardiologist and possibly a cardiovascular surgeon and genetic counselor.

Medical care includes traditional cardiovascular risk factor management. Beta-blockers are often used to control blood pressure but should be used with caution in those with acute aortic valve regurgitation.

doi:10.3949/ccjm.87a.19140-1
NEURYSM of the thoracic aorta, renal arA tery, or splenic artery is often detected incidentally but can present acutely with dissection or rupture, with a high risk of death or morbidities. Computed tomography angiography (CTA) and magnetic resonance angiography (MRA) are key to characterizing the aneurysm and the rest of the vasculature, while ultrasonography or echocardiography assist in assessment and surveillance, and catheter angiography is the gold standard for renal and splenic aneurysm.

The need for prophylactic intervention is based on aneurysm size, location, growth, and other associated conditions and risk factors in the individual patient. Management strategies include surgery, which is mandatory in the acute setting and in cases of challenging anatomy, and endovascular techniques. Regular imaging surveillance is critical after diagnosis and after aneurysm interventions.

In this, the first of 2 articles, we discuss thoracic aortic aneurysm (TAA); in the second article, we will discuss renal artery and splenic artery aneurysm.

\section{WHAT IS THE CLINICAL IMPORTANCE OF TAA?}

TAA is clinically important because of the risk of devastating complications-acute aortic syndromes such as aortic dissection and rupture., ${ }^{1,2}$

Type A aortic dissection (ie, originating in the ascending aorta) is a fatal condition with dismal in-hospital mortality rates of $57 \%$ without emergency surgery and $17 \%$ to $25 \%$ with emergency surgery in national and international registries despite advances in management. ${ }^{3,4}$ The mortality rate is much lower but still significant in expert aortic centers of excellence, 


\section{TABLE 1}

Thoracic aortic aneurysm: Risk factors, associations, and causes

\author{
Risk factors \\ Older age \\ Male sex \\ Hypertension \\ Smoking \\ Hypercholesterolemia \\ Weight-lifting \\ Cocaine use \\ Trauma \\ Cardiovascular associations \\ Atherosclerosis \\ Bicuspid aortic valve \\ Other aneurysm \\ Prior aortic dissection \\ Aortic coarctation
}

\section{Genetic causes}

Familial thoracic aortic aneurysm

Marfan syndrome

Loeys-Dietz syndrome

Ehlers-Danlos syndrome

Turner syndrome

Autosomal-dominant polycystic kidney disease

The risk

of rupture

or dissection

decides

who requires

prophylactic

intervention
Shprintzen-Goldberg (craniosynostosis) syndrome

\section{Inflammatory causes \\ Takayasu arteritis \\ Giant-cell arteritis \\ Behçet arteritis \\ Ankylosing spondylitis}

\section{Infective causes}

Mycotic aortitis

Syphilis

\section{Idiopathic}

such as the $4 \%$ to $7 \%$ reported by Cleveland Clinic. ${ }^{5}$ The incidence of combined TAA and aortic dissection has been reported to be 6 to 13 per 100,000 per year, ${ }^{6-8}$ although this would underestimate clinically silent TAA. ${ }^{3}$

There are no effective preventive strategies for TAA to date; thus, early detection, surveillance, and treatment are critical to improving outcomes. Guidelines are available. 1,2,9

\section{WHO IS AT RISK?}

Risk factors for TAA (Table 1) are abundant in modern society and include older age, male sex, hypertension, smoking, and atherosclerosis. No wonder, then, that the incidence of TAA and the number of surgical repairs are increasing. ${ }^{2,10}$

Genetic conditions associated with TAA such as Marfan syndrome are less common but nevertheless important because the prognosis and management are different. ${ }^{1,2,9}$ Some risk factors or conditions increase wall stress, while others increase medial degeneration. ${ }^{10}$ Although only $5 \%$ of cases of TAA are associated with genetic syndromes, another 20\% are in patients who have a family history of TAA, which has important implications for assessment, management, and counselling. ${ }^{11}$ And many cases are idiopathic, lacking obvious causes or risk factors.

\section{HOW IS TAA DISCOVERED?}

Most cases of TAA are asymptomatic and are discovered either incidentally on imaging or as part of dedicated screening for those at risk. ${ }^{1}$ That said, possible symptoms include chest, abdominal, or back pain, dyspnea, cough, dysphagia, hoarseness, claudication, and cerebrovascular events.

The clinical history should be directed at symptoms, risk factors, and family history.

Physical examination should focus on the cardiac, neurologic, and peripheral vascular systems and should include blood pressure (and how it differs in different limbs), pulses, murmurs, and bruits, and other signs specific to associated conditions. ${ }^{1}$

Basic investigations that can detect possible abnormalities associated with TAA include electrocardiography (showing ischemic changes or myocardial hypertrophy), chest radiography (showing a widened mediastinum or prominent aortic shadow), and blood tests, including complete blood cell count, metabolic profile, and markers of inflammation, coagulation, and myocardial injury, many of which help in the differential diagnosis of TAA vs acute aortic syndromes. ${ }^{1,9}$

\section{WHAT IS A NORMAL-SIZE AORTA?}

Although aneurysm is generally defined as an increase of more than $50 \%$ of the normal arterial diameter, cardiac imaging guidelines have clear dimension thresholds for different severities of TAA dilation. ${ }^{9,10}$ 


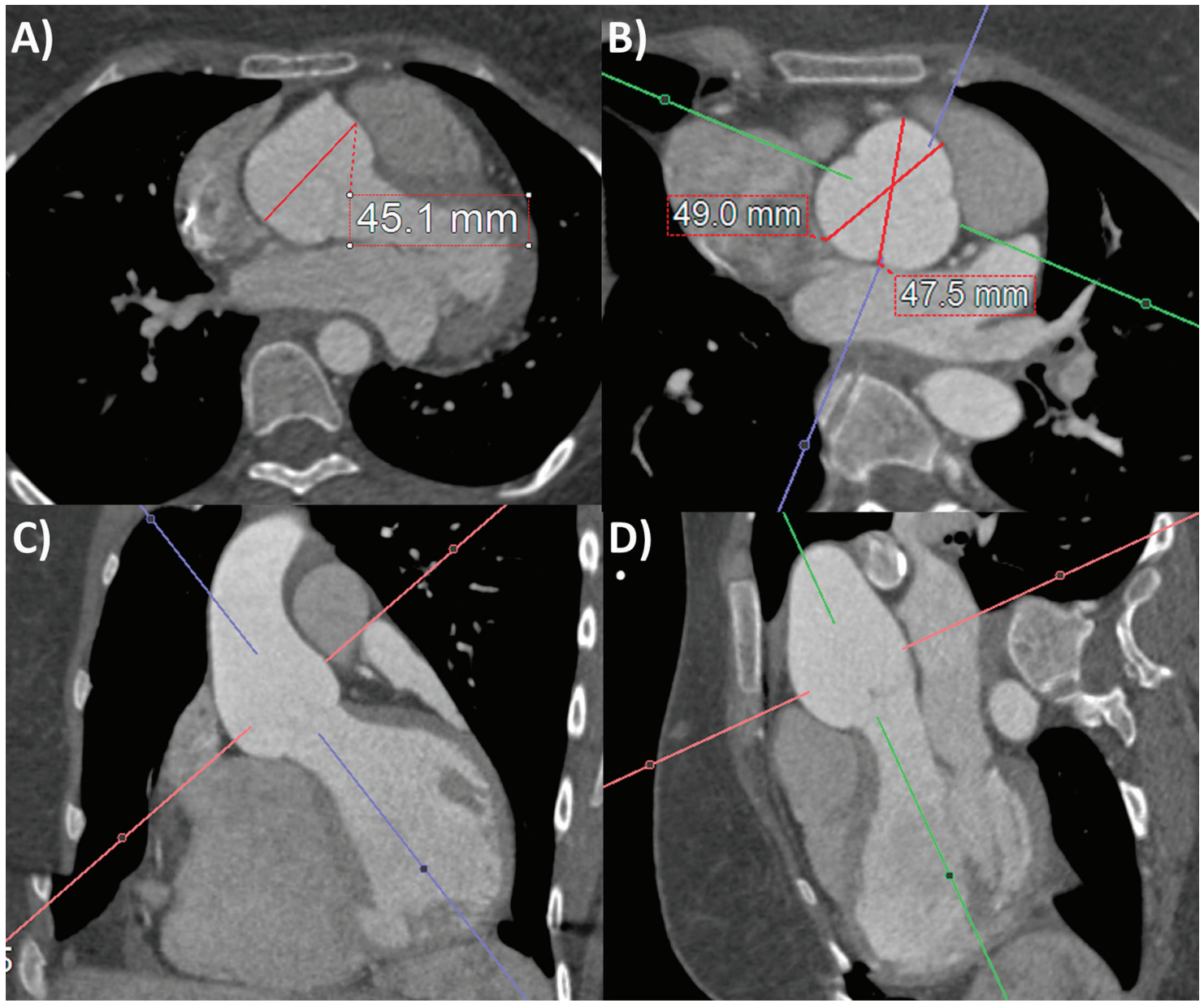

Figure 1. Computed tomography angiography aortic root measurements on (A) axial source image and (B-D) 3-dimensional multiplanar reconstruction (3-D-MPR) double-oblique planes. Note that without 3-D-MPR, the aortic root size is underestimated (A). Also note that sinuscommissure measurements are often slightly less than sinus-sinus measurements in (B).

The aorta is larger in men and in larger people generally, and therefore sex and body size are taken into account when determining the normal ranges and severity thresholds. ${ }^{9}$ The aorta also tends to increase in size with age. The upper limit of normal for aortic dimensions is 2 standard deviations above the mean diameter in a population of healthy adults.

Aortic dimensions are measured at right angles to the direction of blood flow. On echocardiography, the standardized aortic measurements are taken in the end-diastolic frame and from leading edge to leading edge for reproducibility. On CTA and MRA, measurements are from inner edge to inner edge, from aortic sinus to sinus, or from sinus to commissure (often about $2 \mathrm{~mm}$ smaller than from sinus to sinus; Figure 1).12,13 The full thoracic aortic study should include measurement of all segments: aortic sinus; sinotubular junction; proximal, mid, and distal ascending aorta; aortic arch; and descending aorta, as well as the maximal dimensions, branch involvement, and surgical anastomoses. ${ }^{9}$ The aortic walls should be examined for calcification, thrombus, dissection, hematoma, and infection.

\section{WHAT IMAGING MODALITIES ARE USED?}

Aortic imaging remains central to TAA diagnosis and surveillance. ${ }^{1,2,9}$

Three-dimensional multiplanar reconstruction software for CTA and MRA has revolutionized measurement of the aorta, recon-
3-D CTA

and MRA have revolutionized measurement of the aorta 


\section{TABLE 2}

\section{Imaging options for assessing thoracic aortic aneurysm}

\begin{tabular}{llllll} 
Considerations & TTE & TEE & CTA & MRA & Aortography \\
\hline Accuracy of measurement & Medium & Medium & High & High & Low \\
\hline Extent of aortic assessment & Limited & Medium & Entire & Entire & Limited \\
\hline Detecting acute aortic syndromes & Poor & Medium & High & High & Poor \\
\hline Aortic regurgitation and grading & Yes & Yes & No & Yes & Limited \\
\hline Portable & Yes & Yes & No & No & No \\
\hline Contrast & No & No & Yes & Yes & Yes \\
\hline Radiation & No & No & Yes & No & Yes \\
\hline Cost & Low & Medium & Medium & High & High \\
\hline Invasive procedure & No & Yes & No & No & Yes \\
\hline Recommended line of investigation & Second & Third & First & Second & Third
\end{tabular}

CTA = computed tomography angiography; MRA = magnetic resonance angiography; TEE = transesophageal echocardiography; TTE $=$ transthoracic echocardiography

CTA is the recommended first-line imaging for assessing TAA structing source images into double-oblique planes to ensure measurements are taken perpendicular to the lumen (Figure 1).,2,9

Echocardiographic aortic root measurement has the strongest evidence base for guiding intervention, and its thresholds have been extrapolated to other modalities and aortic locations. Clinicians need to be aware of these concepts and limitations to select the best imaging modality, perform measurements, and interpret the results. Table 2 lists the uses and limitations of 5 imaging modalities for TAA, modified from American Society of Echocardiography guidelines. ${ }^{9}$

Transthoracic echocardiography (TTE) has the advantages of portability, accessibility, and low cost. The operator should interrogate the aortic root and ascending aorta in the parasternal long-axis views, parts of the arch and descending thoracic aorta in the suprasternal view, and a segment of the abdominal aorta in the subcostal view. ${ }^{1,9}$

Transesophageal echocardiography (TEE) has a limited role in the primary assessment of TAA unless concurrent structural cardiac disease is suspected. It can visualize a greater extent of the thoracic aorta than TTE and with superior spatial resolution, including with 3-dimensional techniques. It can also be used for intraoperative evaluation as well as a contrastfree imaging option for diagnosing acute aortic syndromes. ${ }^{9}$ The aortic root and ascending aorta can be visualized in the midtransesophageal long-axis view at 100 to 140 degrees; the aortic valve and root in the short-axis view at 45 to 60 degrees; and the descending thoracic aorta up close at 0 degrees in the short-axis view and 90 degrees in the long-axis view, where atheroma and dissection flaps can be visualized up to the aortic arch with probe withdrawal. ${ }^{1,14}$

CTA is the recommended first-line imaging for assessing TAA, having high spatial resolution and a short scan time (3-4 seconds for the thoracic aorta, $<10$ seconds for thoracoabdominal and iliofemoral vessels), enabling assessment of all segments and walls of the thoracic aorta with a 3-D dataset. Radiation and contrast use are limitations. Electrocardiographic gating of CTA is recommended to reduce motion artifacts (Figure 2 ).

Noncontrast CT of the aorta may add value if assessing for intramural hematoma or vascular calcification, or if contrast is contraindicated. ${ }^{15}$ 


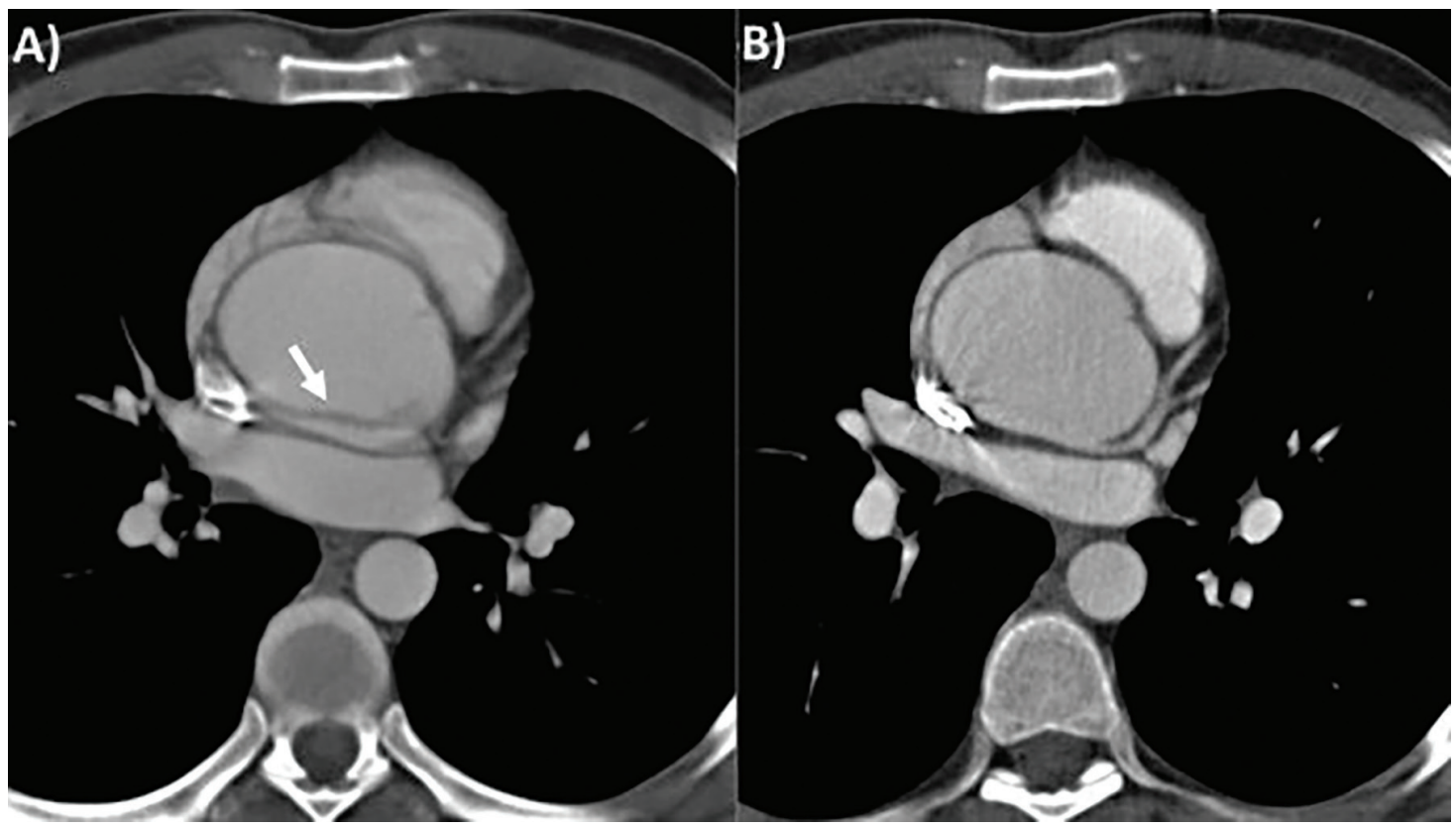

Figure 2. Computed tomography of thoracic aortic aneurysm without (A) and with (B) electrocardiographic gating. Note that the motion artifact indicated by the white arrow in $(A)$ is not seen in (B).

MRA also provides a high-resolution 3-D dataset for aortic assessment without the use of radiation, but has longer scan time, higher cost, and lower availability than echocardiography and CT, and so it is a second-line modality. ${ }^{9}$ Relevant magnetic resonance techniques include contrast-enhanced MRA, cine bright-blood sequences such as steady-state free precession and black-blood spin-echo sequences with or without inversion recovery. MRA can further assess aortic physiology, for example, measuring flow by phase-contrast velocity-encoded imaging, aortic stiffness and elasticity, and shear stress. ${ }^{3,16}$

Both CTA and MRA can also assess for other cardiac and thoracic diseases. CTA or MRA should be performed in every patient diagnosed with TAA to confirm the maximal dimensions and assess the entire length of the aorta. ${ }^{1,2,9}$

Other methods for aortic imaging include invasive aortography with fluoroscopy, positron-emission tomography, and intravascular ultrasonography, although they are never used solely for assessing TAA. ${ }^{1}$

Examples of TAA pathologies are shown in Figure 3.

\section{WHEN SHOULD TAA BE FIXED?}

Table 3 summarizes the American 2010 and European 2014 guidelines and our recommendations on indications for TAA repair. ${ }^{1,2}$ The main determinants include aneurysm dimensions, rate of expansion, and associated conditions. The patient's overall estimated risk of acute aortic syndrome also needs to be balanced with the hospital's expertise and procedural risks for TAA repair. Surgical evaluation is necessary when there are symptoms thought to be related to the TAA, irrespective of other factors. ${ }^{2}$

TAAs grow by 0.7 to $1.9 \mathrm{~mm}$ per year in undilated aortas, but growth can be faster in patients with a dilated aorta or associated conditions. ${ }^{17}$

TAA size is the strongest predictor of acute aortic syndromes. ${ }^{18}$ In patients who have no other conditions, the guidelines recommend surgery when the aortic root, ascending aorta, or aortic arch reaches 5.5 $\mathrm{cm}$ and when the descending aorta reaches $6.0 \mathrm{~cm}(\geq 5.5 \mathrm{~cm}$ with endovascular stenting). ${ }^{1,2}$ This is based on a sharp rise in the risk of aortic dissection when the ascending aorta reaches $6 \mathrm{~cm}$ and the descending aorta reaches $7 \mathrm{~cm} .{ }^{17}$

\section{Absent other conditions, intervention is indicated If the ascending aorta is $\geq 5.5 \mathrm{~cm}$ or the descending aorta is $6.0 \mathrm{~cm}$}




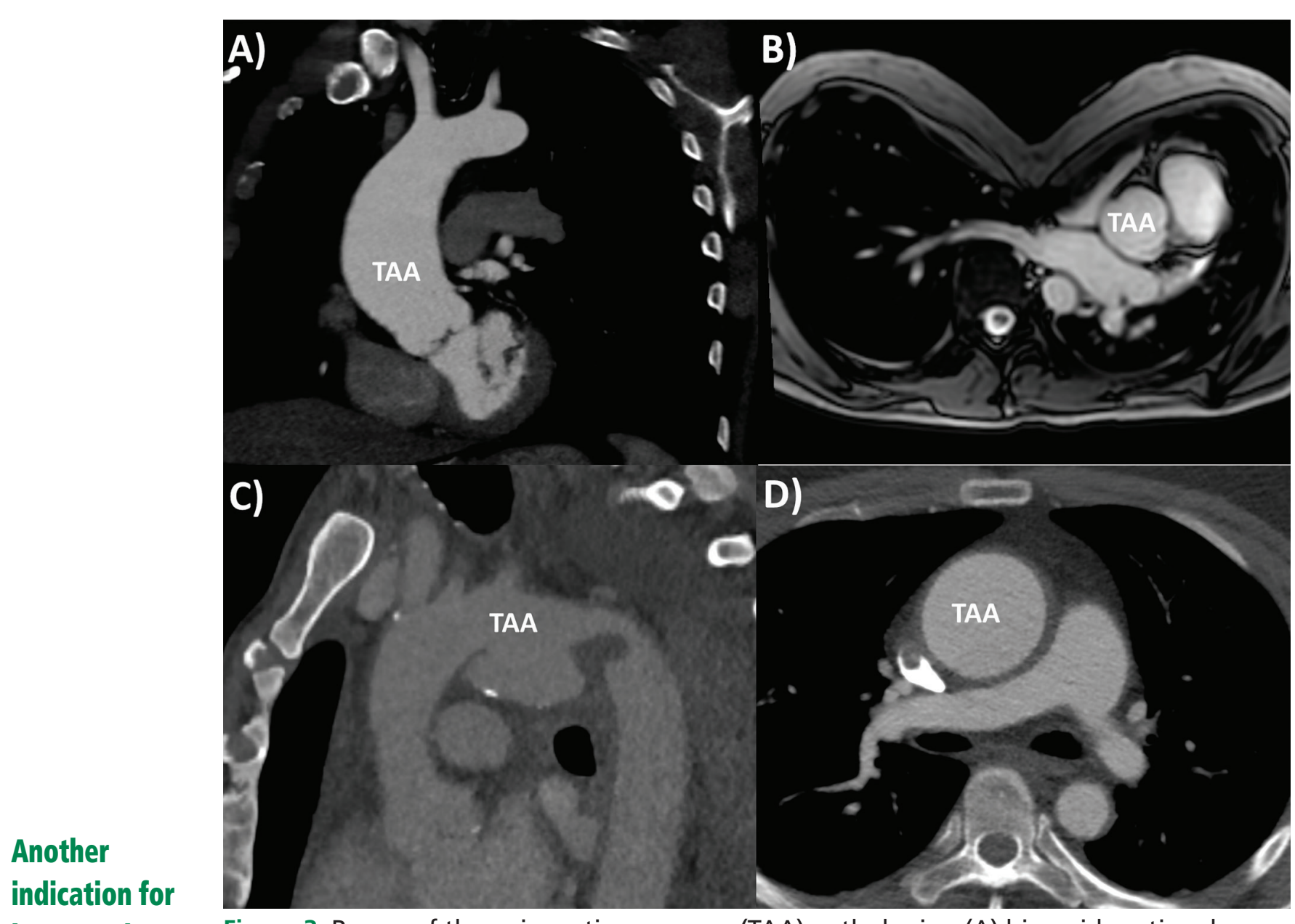

\section{intervention}

is a maximal

cross-sectional

area $\pi r^{2} / H>10$

Figure 3. Range of thoracic aortic aneurysm (TAA) pathologies: (A) bicuspid aortic valve aortopathy on computed tomography (CT), (B) Marfan syndrome with pectus excavatum on magnetic resonance imaging, (C) mycotic aortic arch aneurysm on CT, (D) Takayasu arteritis on $\mathrm{CT}$, with thickened, inflamed aortic wall.

Factors that lower the threshold include associated conditions, faster rate of growth (measured by the same modality and exceeding the margin of error of 3-5 mm/year), and the need for adjacent aneurysm or aortic valve surgery. ${ }^{1,2}$

The American guidelines further emphasize measuring the maximal TAA cross-sectional area. If the maximal TAA cross-sectional area (in $\mathrm{cm}^{2}$ ) divided by height (in meters) is greater than 10 , this would be another indication for intervention. ${ }^{2}$ This threshold was derived from studies from Cleveland Clinic originally applied to patients with bicuspid aortic valves and Marfan syndrome, ${ }^{19,20}$ and more recently in all TAA patients, ${ }^{21}$ with major prognostic implications (Figure 4).

\section{Lower thresholds in associated conditions}

Lower thresholds for intervention are recommended when patients have associated conditions that increase the risk of dissection at smaller dimensions and increase the rate of growth. ${ }^{1,2}$

Bicuspid aortic valve. Recent guidelines have shifted the thresholds for intervention back up to $\geq 5.5 \mathrm{~cm}$, or $\geq 5.0 \mathrm{~cm}$ with risk factors for patients with bicuspid aortic valves, which occur in $1 \%$ to $2 \%$ of the population. ${ }^{1,22}$ (Previously, the threshold was $4.5 \mathrm{~cm}$ or greater.) These patients have a risk of aortic dissection up to 8 times higher than that of the general population..$^{23}$ A Cleveland Clinic study found the risk of aortic dissection in bicuspid aortic valve patients to be elevated at 4.7 to $5.3 \mathrm{~cm}$, but the risk further accelerates beyond 


\section{TABLE 3}

\section{Indications for prophylactic intervention for thoracic aortic aneurysm}

\section{Aneurysm location and associated conditions} ACC/AHA 2010² ESC 2014

Our recommendation

\section{Ascending aorta}

No associated conditions

$\geq 5.5 \mathrm{~cm}(\mathrm{I}-\mathrm{C})^{\mathrm{a}}$

$\geq 0.5 \mathrm{~cm} /$ year growth $(\mathrm{I}-\mathrm{C})$ $\geq 5.5 \mathrm{~cm}(\mathrm{I}-\mathrm{C})$, lower if small stature, rapid progression, aortic regurgitation (AR), pregnancy, patient preference (Ila-C)

\begin{tabular}{ll}
\hline Aortic valve surgery planned & $>4.5 \mathrm{~cm}(\mathrm{I}-\mathrm{C})$ \\
\hline Marfan syndrome & $4.0-5.0 \mathrm{~cm}(\mathrm{I}-\mathrm{C})$ \\
& $\pi \mathrm{r}^{2} / \mathrm{H}>10$ (Ila-C)
\end{tabular}

$>4.5 \mathrm{~cm}$

$\geq 5.0 \mathrm{~cm}(\mathrm{I}-\mathrm{C})$ $>4.5 \mathrm{~cm}$ with risk factors or family $\pi \mathrm{r}^{2} / \mathrm{H}>10$ history (Ila-C) $\geq 0.3 \mathrm{~cm} /$ year growth, severe AR, pregnancy desired (Ila-C)

\begin{tabular}{ll}
\hline Bicuspid aortic valve & $\geq 4.0-5.0 \mathrm{~cm}(\mathrm{I}-\mathrm{C})$ \\
& $\pi \mathrm{r}^{2} / \mathrm{H}>10(\mathrm{Ila}-\mathrm{C})$
\end{tabular}

\section{$\geq 5.5 \mathrm{~cm}$ without risk factors (I-C) $\quad \geq 5.0 \mathrm{~cm}$ without risk factors} $\geq 5.0 \mathrm{~cm}$ with risk factors, $\quad \geq 4.5 \mathrm{~cm}$ with risk factors family history, hypertension, aortic $\pi r^{2} / \mathrm{H}>10$ coarctation (I-C) $\geq 4.5 \mathrm{~cm}$ if AVR planned (I-C) $\geq 0.3 \mathrm{~cm} /$ year growth (Ila-C)

\begin{tabular}{|c|c|c|c|}
\hline Turner syndrome & $\begin{array}{l}4.0-5.0 \mathrm{~cm}(\mathrm{I}-\mathrm{C}) \\
\pi \mathrm{r}^{2} / \mathrm{H}>10 \text { (Ila-C) }\end{array}$ & $\begin{array}{l}\text { Indexed aortic diameter } \geq 27.5 \\
\mathrm{~mm} / \mathrm{m}^{2}\end{array}$ & $\begin{array}{l}\geq 27.5 \mathrm{~mm} / \mathrm{m}^{2} \\
\pi \mathrm{r}^{2} / \mathrm{H}>10\end{array}$ \\
\hline $\begin{array}{l}\text { Loeys-Dietz syndrome } \\
\text { (apply to TGFBR1 or TGFBR2 } \\
\text { mutation) }\end{array}$ & $\begin{array}{l}\geq 4.2 \mathrm{~cm} \text { (TEE) (Ila-C) } \\
\geq 4.4-4.6 \mathrm{~cm} \text { (CTA/MRA) } \\
\text { (Ila-C) }\end{array}$ & $\begin{array}{l}\geq 5.0 \mathrm{~cm} \mathrm{(I-C)} \\
\geq 4.5 \mathrm{~cm} \text { with risk factors (Ila-C) }\end{array}$ & $\begin{array}{l}\geq 4.5 \mathrm{~cm} \\
\pi r^{2} / \mathrm{H}>10\end{array}$ \\
\hline Ehlers-Danlos syndrome & $\begin{array}{l}4.0-5.0 \mathrm{~cm}(\mathrm{I}-\mathrm{C}) \\
\pi \mathrm{r}^{2} / \mathrm{H}>10 \text { (Ila-C) }\end{array}$ & $\begin{array}{l}\text { No specific threshold } \\
\text { recommended }\end{array}$ & $\begin{array}{l}\geq 4.5 \mathrm{~cm} \\
\pi r^{2} / H>10\end{array}$ \\
\hline Familial TAA & $\begin{array}{l}4.0-5.0 \mathrm{~cm}(\mathrm{I}-\mathrm{C}) \\
\pi \mathrm{r}^{2} / \mathrm{H}>10 \text { (Ila-C) }\end{array}$ & $\begin{array}{l}\text { No specific threshold } \\
\text { recommended }\end{array}$ & $\begin{array}{l}\geq 4.5 \mathrm{~cm} \\
\pi r^{2} / \mathrm{H}>10\end{array}$ \\
\hline
\end{tabular}

\section{Aortic arch}

None

$$
\geq 5.5 \mathrm{~cm} \text { (IIa-B) }
$$

$\geq 5.5 \mathrm{~cm}$

$\pi \mathrm{r}^{2} / \mathrm{H}>10$ descending TAA surgery (Ila-C)

\section{Descending aorta}

\begin{tabular}{llll} 
Stent graft & $\geq 5.5 \mathrm{~cm}(\mathrm{I}-\mathrm{B})$ & $\geq 5.5 \mathrm{~cm}$ (Ila-C) & $\geq 5.5 \mathrm{~cm}$ \\
\hline Surgery & $\begin{array}{l}\geq 6.0 \mathrm{~cm}(\mathrm{I}-\mathrm{C}) \text { (include high } \\
\text { risk, thoracoabdominal) }\end{array}$ & $\geq 6.0 \mathrm{~cm}$ (Ila-C) & $\geq 6.0 \mathrm{~cm}$ \\
\hline $\begin{array}{l}\text { Surgery with degenerative, } \\
\text { traumatic or saccular TAA, }\end{array}$ & $\geq 5.5 \mathrm{~cm} \mathrm{(I-B)}$ & $\begin{array}{l}\text { No specific threshold } \\
\text { recommended }\end{array}$ & $\geq 5.5 \mathrm{~cm}$ \\
Op & &
\end{tabular}
or postoperative pseudoaneurysm

\begin{tabular}{|c|c|c|c|}
\hline $\begin{array}{l}\text { Surgery with connective } \\
\text { tissue disorder like Marfan } \\
\text { or Loeys-Dietz syndrome }\end{array}$ & $\begin{array}{l}\text { Lower threshold than }>6 \\
\mathrm{~cm}(\mathrm{I}-\mathrm{C})\end{array}$ & Lower threshold than $>6 \mathrm{~cm}$ & $\geq 5.5 \mathrm{~cm}$ \\
\hline
\end{tabular}


A

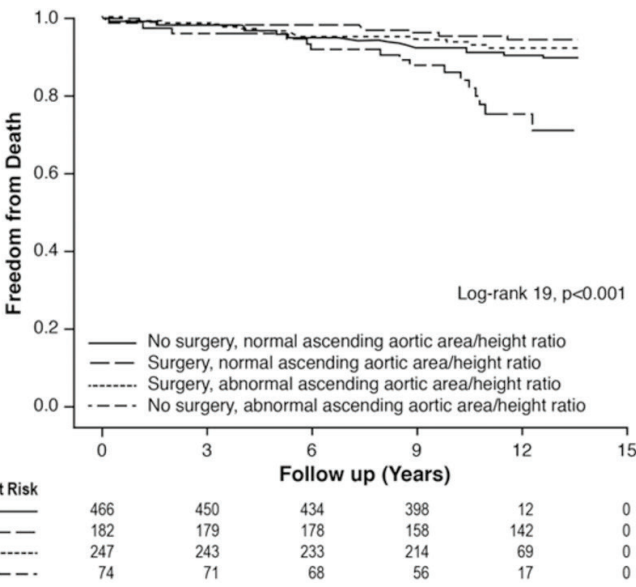

B

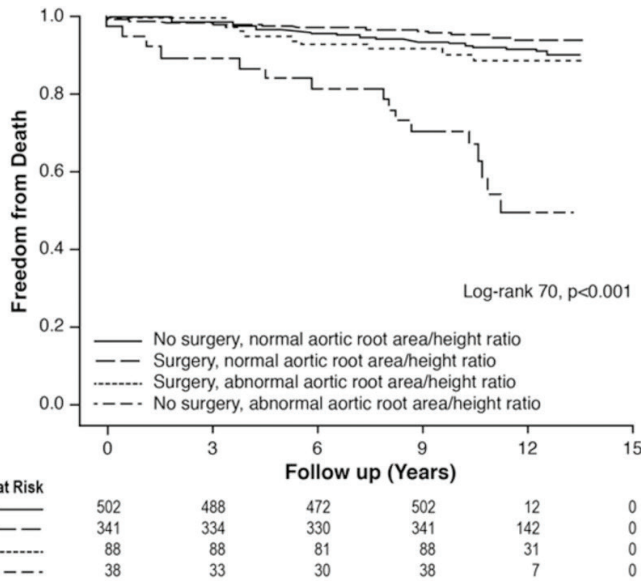

Figure 4. Cross-sectional area-to-height ratio and management-stratification Kaplan-Meier survival curves for (A) aortic root and (B) ascending aorta in 969 consecutive patients with bicuspid aortic valve with proximal aorta diameter $\geq 4 \mathrm{~cm}$, who underwent gated contrastenhanced thoracic computed tomography or magnetic resonance angiography. Note the worse outcomes for those with aortic root area-to-height ratio $>10 \mathrm{~cm}^{2} / \mathrm{m}$, in whom surgery makes a big difference in survival.

Reprinted from Masri A, Kalahasti V, Svensson LG, et al. Aortic cross-sectional area/height ratio and outcomes in patients with bicuspid aortic valve and a dilated ascending aorta. Circ Cardiovasc Imaging 2017; 10(6):e006249. doi:10.1161/CIRCIMAGING.116.00624

Aneurysm

of the

ascending aorta

mandates

surgical repair;

aneurysm of

the descending

aorta can be

managed with

endovascular

procedures
$5.3 \mathrm{~cm}$, so a $5.0-\mathrm{cm}$ threshold for intervention rather than a higher one may indeed be preferred in these patients. ${ }^{24}$

Marfan syndrome. The threshold for intervention is 4.5 to $5.0 \mathrm{~cm}$, depending on risk factors. ${ }^{1}$

Loeys-Dietz syndrome. There are mixed views for the threshold of intervention, ie, whether it should be the same as in Marfan syndrome or even lower. ${ }^{1,2,25}$

Turner syndrome is associated with short stature and greater risk of rupture for the same aorta size, so indexed measurements are preferred. ${ }^{26}$ It is also associated with bicuspid aortic valve and aortic coarctation, so concurrent cardiovascular surgery is often required.

Ehlers-Danlos syndrome is associated with tissue fragility, making surgery challenging. Therefore, surgery remains controversial in this condition, and most patients are conservatively managed. ${ }^{27}$

\section{HOW SHOULD TAA BE MONITORED?}

Patients with TAA should be referred to a cardiologist (and a surgeon, if approaching or exceeding surgical criteria) for optimal decisionmaking in surveillance and management.

The first thing to consider is the imaging modality to use. Table 4 summarizes the guidelines and our recommendations for TAA surveillance, using TTE, CTA, and MRA. ${ }^{1-3}$

CTA or MRA is useful at baseline to image the entire aorta and check agreement with TTE measurements. If TTE measurements have close agreement with CTA or MRA, then TTE can be used for regular monitoring, although CTA or MRA should still be performed, though less often, for monitoring segments of the aorta not visible on TTE and checking TTE accuracy over time.

If there is poor agreement between TTE and CTA or MRA measurements, or poor visualization of the aorta with TTE, then CTA or MRA should be used instead for regular monitoring. The latter is preferred to avoid radiation exposure, but the former may be necessary if MRA is contraindicated, eg, because of a cardiac device or claustrophobia. ${ }^{3}$ Accurate and reproducible measurements are critical in surveillance, especially when nearing the threshold for intervention.

Once the modality is established, timing of surveillance and guideline recommendations depend on aortic dimensions and growth and presence of associated conditions. ${ }^{1,2,9}$ In the absence of conditions associated with TAA, the recommendation is routine surveillance at the discretion of the clinician, based on 


\section{TABLE 4}

\section{Recommendations for measurement and surveillance of thoracic aortic aneurysms}

\begin{tabular}{|c|c|}
\hline $\begin{array}{l}\text { Associated } \\
\text { conditions }\end{array}$ & ACC/AHA $2010^{2}$ \\
\hline None & $\begin{array}{l}\text { No specific recommendations } \\
\text { except needing surveillance }\end{array}$ \\
\hline $\begin{array}{l}\text { Marfan } \\
\text { syndrome }\end{array}$ & $\begin{array}{l}\text { Measure dimensions and maxi- } \\
\text { mum cross-sectional area } \\
\text { divided by height } \\
\text { TTE at baseline and } 6 \text { months, } \\
\text { CTA or MRA at baseline to } \\
\text { check TTE } \\
\text { If stable and }<4.5 \mathrm{~cm} \text {, then } \\
\text { yearly after, if not then more } \\
\text { frequently }\end{array}$ \\
\hline
\end{tabular}

ESC 2014'

No specific recommendations except needing surveillance
ASE/EACVI $2015^{3}$

Every $1-3$ years

based on risk after diagnosis

Our recommendations

TTE and CTA or MRA at baseline and 6 months; If TAA $<5.0 \mathrm{~cm}$ and stable, then yearly If TAA $\geq 5.0 \mathrm{~cm}$ or growing $>0.5$ $\mathrm{cm} /$ year, then every 6 months and refer to surgeon

TTE and MRA or CTA If no TAA at baseline, TTE yearly, MRA or CTA every 5 years

If any aneurysm is above root, MRA or CTA yearly Refer to 2010 ESC adult congenital disease guidelines ${ }^{35}$
Dimensions with normative values based on age, body surface area, and Z scores

TTE and CTA or MRA

If no TAA at baseline, then every 2-3 years

First TAA diagnosis: 6 months then yearly if stable, $<4.5 \mathrm{~cm}$ and no dissection history; otherwise every 6 months

Postoperatively: 6 months, then yearly if stable CTA or MRA at least every 3 years if using TTE

\begin{tabular}{lll}
\hline $\begin{array}{l}\text { Bicuspid } \\
\text { aortic valve }\end{array}$ & $\begin{array}{l}\text { No specific recommendations } \\
\text { after initial imaging TTE and CTA } \\
\text { or MRA }\end{array}$ & $\begin{array}{l}\text { TTE and CTA or MRA } \\
\text { If no TAA at baseline, repeat TTE } \\
\text { yearly } \\
\text { If TAA }>4.5 \mathrm{~cm} \text { or growing at }>3 \\
\text { mm/year, then do CTA or MRA } \\
\text { to confirm at same time, then } \\
\end{array}$ \\
& yearly
\end{tabular}

Turner Baseline TTE and CTA or MRA

syndrome If no TAA or dissection risk factors, repeat every $5-10$ years
TTE and CTA or MRA at baseline and 6 months

If no TAA, then TTE yearly and CTA or MRA every 2 years First TAA diagnosis: TTE and CTA or MRA yearly if stable $(<0.3$ $\mathrm{cm} /$ year) and $<4.5 \mathrm{~cm}$, otherwise every 6 months and refer to surgeon
TTE and CTA or MRA

If no at baseline, repeat every $3-5$ years

First TAA diagnosis: 6 months then yearly if stable, $<4.5$ $\mathrm{cm}$ and no dissection history; otherwise every 6 months Postoperatively: yearly but individualize

If no TAA: TTE every $3-5$ years for low risk, MRA every 3-5 years for moderate risk, and MRI every 1-2 years for high risk
Index dimensions by body surface area; if indexed diameter $>2 \mathrm{~cm} / \mathrm{m}^{2}$, repeat yearly
TTE + CTA or MRA at baseline and 6 months No TAA: TTE yearly and CTA or MRA every 2 years

First TAA diagnosis: TTE and CTA or MRA yearly if stable $(<0.3$ $\mathrm{cm} /$ year) and $<4.5 \mathrm{~cm}$, otherwise every 6 months and refer to surgeon

TTE + CTA or MRA at baseline and 6 months

Index dimensions by body surface area

No TAA: TTE yearly and CTA or MRA every 2 years Indexed diameter $>2 \mathrm{~cm} / \mathrm{m}^{2}$ : yearly MRA or CTA and refer to surgeon

\begin{tabular}{|c|c|c|c|c|}
\hline Familial TAA & $\begin{array}{l}\text { No specific recommendations } \\
\text { after initial imaging TTE and CTA } \\
\text { or MRA }\end{array}$ & $\begin{array}{l}\text { No specific recommendations } \\
\text { after initial imaging TTE and CTA } \\
\text { or MRA }\end{array}$ & $\begin{array}{l}\text { Follow plan for Marfan syn- } \\
\text { drome, but individualize }\end{array}$ & $\begin{array}{l}\text { TTE + CTA or MRA at baseline } \\
\text { and } 6 \text { months } \\
\text { Follow plan for Marfan syndrome } \\
\text { but individualize risk }\end{array}$ \\
\hline $\begin{array}{l}\text { Loeys-Dietz } \\
\text { syndrome }\end{array}$ & $\begin{array}{l}\text { Baseline and } 6 \text { months TTE and } \\
\text { CTA or MRA, then yearly if } \\
\text { stable } \\
\text { Whole-body MRA }\end{array}$ & $\begin{array}{l}\text { No specific recommendations } \\
\text { after initial imaging TTE and CTA } \\
\text { or MRA }\end{array}$ & $\begin{array}{l}\text { Every } 1-3 \text { years depending } \\
\text { on risk, every } 6 \text { months if } \\
\text { progression }\end{array}$ & $\begin{array}{l}\text { TTE + CTA or MRA at baseline } \\
\text { and } 6 \text { months } \\
\text { Yearly if low risk, }<4.0 \mathrm{~cm} \text { and stable } \\
(<0.3 \mathrm{~cm} / \text { year), otherwise every } \\
6 \text { months and refer to surgeon }\end{array}$ \\
\hline $\begin{array}{l}\text { Ehlers-Danlos } \\
\text { syndrome }\end{array}$ & No specific recommendations & $\begin{array}{l}\text { No specific recommendations, } \\
\text { individualize }\end{array}$ & No specific recommendations & $\begin{array}{l}\text { TTE + CTA or MRA at baseline } \\
\text { and } 6 \text { months } \\
\text { No specific recommendation for } \\
\text { surveillance }\end{array}$ \\
\hline
\end{tabular}

$\mathrm{ACC}=$ American College of Cardiology; $\mathrm{AHA}=$ American Heart Association; ASE = American Society of Echocardiography;

$\mathrm{CTA}$ = computed tomography angiography; EACVI = European Association of Cardiovascular Imaging; ESC = European Society of Cardiology; MRA = magnetic resonance angiography; $\mathrm{MRI}=$ magnetic resonance imaging; TAA = thoracic aortic aneurysm; TTE = transthoracic echocardiography 
individual risk. On the other hand, an early follow-up scan (6 months after initial TAA diagnosis) is recommended to assess for growth of the aneurysm in patients who have genetic conditions, and annually thereafter if measurements have been stable or more frequently if there is accelerated growth.

The measurements recommended may also differ by condition, such as comparing to normalized values by age, sex, and body surface area and using $\mathrm{Z}$ scores in those with Marfan syndrome and indexing to body surface area in those with Turner syndrome. ${ }^{9}$ No specific recommendations for TAA surveillance and intervention for Ehlers-Danlos syndrome have been made because there is no evidence that intervening is beneficial. ${ }^{1,2,9}$

\section{DO DRUGS SLOW THE RATE OF TAA EXPANSION?}

TAA patients should be referred to a cardiologist to provide guideline-based medical management of the aorta, and to a cardiac surgeon when nearing a threshold for intervention. ${ }^{1,2}$

Blood pressure control is the cornerstone of medical management of TAA, as it makes pathophysiologic sense to reduce aortic wall shear stress and expansion. However, many recommendations have been extrapolated from studies in patients with Marfan syndrome, with mixed results.

A randomized trial ${ }^{28}$ found beta-blockers reduced expansion and even mortality in patients with Marfan syndrome with TAA, though this was not consistently reported in other studies. Nevertheless, beta-blockers are routinely prescribed in TAA, with adequate response represented by reduction in both blood pressure and heart rate, although they should not be used in those with significant aortic regurgitation. ${ }^{1}$

There is also some mixed evidence from randomized trials supporting the use of angiotensin II receptor blockers ${ }^{10,29}$ and angiotensin-converting enzyme inhibitors. ${ }^{30}$

The optimal blood pressure target remains controversial. The European guidelines advocate $140 / 90 \mathrm{~mm} \mathrm{Hg},{ }^{1}$ while the American guidelines say $130 / 80 \mathrm{~mm} \mathrm{Hg}$ in those with diabetes or chronic renal disease and 140/90 $\mathrm{mm} \mathrm{Hg}$ in those without. ${ }^{2}$

Statins were seen in one study to reduce events in patients with abdominal aortic aneurysm but not those with TAA, so they are not routinely recommended for TAA. ${ }^{31}$ Nevertheless, many patients with TAA have concurrent atherosclerotic disease that would benefit from statin therapy.

\section{HOW SHOULD TAA BE FIXED?}

Interventions for TAA vary widely in complexity and are classified by location and by modality. Patients should be referred to a highvolume cardiac surgery center with aortic expertise for management to optimize outcomes.

Aneurysm of the ascending aorta mandates surgical repair with median sternotomy, cardiopulmonary bypass, and circulatory arrest. ${ }^{1,2}$ Considerations include the need to operate on the aortic valve (prosthetic valve composite graft or valve-sparing), aortic root (requiring coronary reimplantation), arch (complete or partial, brain protection with hypothermia, and perfusion method), and sometimes the descending aorta.

On the other hand, aneurysm in the descending aorta can be addressed with endovascular repair using percutaneous access in suitable anatomy, with or without arch-vessel transposition (debranching). ${ }^{1}$ The potential benefits are lower perioperative mortality risk and faster recovery than with surgery, although late complications such as graft leak, migration, and rupture can occur, and the durability is unknown. . $2,33^{2}$

Surgery is the alternative option, with a higher threshold of aortic dimensions for intervention. ${ }^{1}$ It is done by thoracotomy and often without cardiopulmonary bypass while protecting the spinal cord. High surgical risk and restricted life expectancy favor endovascular repair, while genetic syndromes, peripheral vascular disease, and unfavorable anatomy favor surgery. ${ }^{1,2} \mathrm{~A}$ hybrid approach for surgery of the ascending aorta, arch, or both and endovascular repair for the descending aorta is sometimes considered in extensive TAA.

\section{WHAT ELSE SHOULD BE MANAGED?}

Management of TAA is multidisciplinary, with many aspects beyond medications and interventions. Patient education regarding warning symptoms and signs of TAA complications warranting immediate medical at- 
tention is important. ${ }^{1,2}$ Cardiovascular risk reduction is important, with nonpharmacologic measures such as healthy diet and smoking cessation, which have positive effects on blood pressure and lipids.

Exercise is controversial in patients with TAA. Although aerobic activity should probably be encouraged, weight-training activities such as heavy lifting should be avoided, particularly in those with genetic conditions such as Marfan syndrome or Loeys-Dietz syndrome.

There is also a weak association of acute aortic syndromes with fluoroquinolones, so avoidance may be considered. ${ }^{34}$

Counseling should be considered in patients with genetic conditions associated with TAA, women considering pregnancy or who are pregnant, and patients with indications for aortic interventions but who are being conservatively managed because of medical comorbidities and surgical risk.
In patients with genetic syndromes or bicuspid aortic valves who develop TAA, counseling and family screening starting with first-degree relatives (and beyond if multiple family members are positive) are important. ${ }^{1,2}$ Screening involves TTE, preferably CTA or MRA (used more because of no radiation), and genetic testing. If one or more first-degree relatives of a TAA patient are also found to have TAA, referral to a clinical geneticist for further testing and counseling is recommended. The implicated genes include FBN1 for Marfan syndrome; TGFBR1, TGFBR2, SMAD3, TGFB2, and TGFB3 for LoeysDietz syndrome, COL5A1, COL5A2, and COL3A1 for Ehlers-Danlos syndrome, and $45 X O$ for Turner syndrome. ${ }^{1,35}$ Early detection of TAAs with surveillance and intervention have the potential to improve outcomes for patients and family members.

\section{REFERENCES}

1. Erbel R, Aboyans V, Boileau C, et al. 2014 ESC guidelines on the diagnosis and treatment of aortic diseases: document covering acute and chronic aortic diseases of the thoracic and abdominal aorta of the adult. The Task Force for the Diagnosis and Treatment of Aortic Diseases of the European Society of Cardiology (ESC). Eur Heart J 2014; 35(41):2873-2926. doi:10.1093/eurheartj/ehu281

2. Hiratzka LF, Bakris GL, Beckman JA, et al. 2010 ACCF/AHA/AATS/ ACR/ASA/SCA/SCAI/SIR/STS/SVM guidelines for the diagnosis and management of patients with thoracic aortic disease: a report of the American College of Cardiology Foundation/American Heart Association Task Force on Practice Guidelines, American Association for Thoracic Surgery, American College of Radiology, American Stroke Association, Society of Cardiovascular Anesthesiologists, Society for Cardiovascular Angiography and Interventions, Society of Interventional Radiology, Society of Thoracic Surgeons, and Society for Vascular Medicine. Circulation 2010; 121(13):e266-e369. doi:10.1161/CIR.0b013e3181d4739e

3. Evangelista A, Isselbacher EM, Bossone E, et al. Insights from the International Registry of Acute Aortic Dissection: a 20-year experience of collaborative clinical research. Circulation 2018; 137(17):18461860. doi:10.1161/CIRCULATIONAHA.117.031264

4. Lee TC, Kon Z, Cheema FH, et al. Contemporary management and outcomes of acute type A aortic dissection: an analysis of the STS adult cardiac surgery database. J Card Surg 2018; 33(1):7-18. doi:10.1111/jocs.13511

5. Cleveland Clinic. Heart, Vascular \& Thoracic Institute (Miller Family) outcomes. Aortic surgery. Accessed August 5, 2020. https:// my.clevelandclinic.org/departments/heart/outcomes/424-aorticsurgery.

6. Clouse WD, Hallett JW Jr, Schaff HV, Gayari MM, Ilstrup DM, Melton LJ 3rd. Improved prognosis of thoracic aortic aneurysms: a population-based study. JAMA 1998; 280(22):1926-1929. doi:10.1001/jama.280.22.1926

7. Howard DP, Banerjee A, Fairhead JF, et al. Population-based study of incidence and outcome of acute aortic dissection and premorbid risk factor control: 10-year results from the Oxford Vascular Study. Circulation 2013; 127(20):2031-2037. doi:10.1161/CIRCULATIONAHA.112.000483
8. Olsson C, Thelin S, Ståhle E, Ekbom A, Granath F. Thoracic aortic aneurysm and dissection: increasing prevalence and improved outcomes reported in a nationwide population-based study of more than 14,000 cases from 1987 to 2002. Circulation 2006; 114(24):2611-2618. doi:10.1161/CIRCULATIONAHA.106.630400

9. Goldstein SA, Evangelista A, Abbara S, et al. Multimodality imaging of diseases of the thoracic aorta in adults: from the American Society of Echocardiography and the European Association of Cardiovascular Imaging: endorsed by the Society of Cardiovascular Computed Tomography and Society for Cardiovascular Magnetic Resonance. J Am Soc Echocardiogr 2015; 28(2):119-182. doi:10.1016/j.echo.2014.11.015

10. Goldfinger JZ, Halperin JL, Marin ML, Stewart AS, Eagle KA, Fuster V. Thoracic aortic aneurysm and dissection. J Am Coll Cardiol 2014; 64(16):1725-1739. doi:10.1016/j.jacc.2014.08.025

11. Coady MA, Davies RR, Roberts $\mathbf{M}$, et al. Familial patterns of thoracic aortic aneurysms. Arch Surg 1999; 134(4):361-367. doi:10.1001/archsurg.134.4.361

12. Lin FY, Devereux RB, Roman MJ, et al. Assessment of the thoracic aorta by multidetector computed tomography: age- and sex-specific reference values in adults without evident cardiovascular disease. J Cardiovasc Comput Tomogr 2008; 2(5):298-308. doi:10.1016/j.jcct.2008.08.002

13. Hager A, Kaemmerer H, Rapp-Bernhardt U, et al. Diameters of the thoracic aorta throughout life as measured with helical computed tomography. J Thorac Cardiovasc Surg 2002; 123(6):1060-1066. doi:10.1067/mtc.2002.122310

14. Seward JB, Khandheria BK, Freeman WK, et al. Multiplane transesophageal echocardiography: image orientation, examination technique, anatomic correlations, and clinical applications. Mayo Clin Proc 1993; 68(6):523-551. doi:10.1016/s0025-6196(12)60367-x

15. Nakayama Y, Awai K, Funama Y, et al. Lower tube voltage reduces contrast material and radiation doses on 16-MDCT aortography. AJR Am J Roentgenol 2006; 187(5):W490-W497. doi:10.2214/AJR.05.0471

16. Boonyasirinant $T$, Rajiah $\mathbf{P}$, Setser RM, et al. Aortic stiffness is increased in hypertrophic cardiomyopathy with myocardial fibrosis: novel insights in vascular function from magnetic resonance imaging. J Am Coll Cardiol 2009; 54(3):255-262. doi:10.1016/j.jacc.2009.03.060

17. Elefteriades JA. Natural history of thoracic aortic aneurysms: indica- 
tions for surgery, and surgical versus nonsurgical risks. Ann Thorac Surg 2002; 74(5):S1877-S1898. doi:10.1016/s0003-4975(02)04147-4

18. Davies RR, Goldstein LJ, Coady MA, et al. Yearly rupture or dissection rates for thoracic aortic aneurysms: simple prediction based on size. Ann Thorac Surg 2002; 73(1):17-28. doi:10.1016/s0003-4975(01)03236-2

19. Svensson LG, Khitin L. Aortic cross-sectional area/height ratio timing of aortic surgery in asymptomatic patients with Marfan syndrome. J Thorac Cardiovasc Surg 2002; 123(2):360-361. doi:10.1067/mtc.2002.118497

20. Svensson LG, Kim KH, Lytle BW, Cosgrove DM. Relationship of aortic cross-sectional area to height ratio and the risk of aortic dissection in patients with bicuspid aortic valves. J Thorac Cardiovasc Surg 2003; 126(3):892-893. doi:10.1016/s0022-5223(03)00608-1

21. Masri A, Kalahasti V, Svensson LG, et al. Aortic cross-sectional area/height ratio and outcomes in patients with bicuspid aortic valve and a dilated ascending aorta. Circ Cardiovasc Imaging 2017; 10(6):e006249. doi:10.1161/CIRCIMAGING.116.006249

22. Hiratzka LF, Creager MA, Isselbacher EM, et al. Surgery for aortic dilatation in patients with bicuspid aortic valves: a statement of clarification from the American College of Cardiology/American Heart Association Task Force on Clinical Practice Guidelines. J Am Coll Cardiol 2016; 67(6):724-731. doi:10.1016/j.jacc.2015.11.006

23. Tzemos N, Therrien J, Yip J, et al. Outcomes in adults with bicuspid aortic valves. JAMA 2008; 300(11):1317-1325.

doi:10.1001/jama.300.11.1317

24. Wojnarski CM, Svensson LG, Roselli EE, et al. Aortic dissection in patients with bicuspid aortic valve-associated aneurysms. Ann Thorac Surg 2015; 100(5):1666-1674. doi:10.1016/j.athoracsur.2015.04.126

25. Loeys BL, Schwarze U, Holm T, et al. Aneurysm syndromes caused by mutations in the TGF-beta receptor. N Engl J Med 2006; 355(8):788798. doi:10.1056/NEJMoa055695

26. Matura LA, Ho VB, Rosing DR, Bondy CA. Aortic dilatation and dissection in Turner syndrome. Circulation 2007; 116(15):1663-1670. doi:10.1161/CIRCULATIONAHA.106.685487

27. Shalhub S, Byers PH, Hicks KL, et al. A multi-institutional experience in the aortic and arterial pathology in individuals with genetically confirmed vascular Ehlers-Danlos syndrome. J Vasc Surg 2019;
70(5):1543-1554. doi:10.1016/j.jvs.2019.01.069

28. Shores J, Berger KR, Murphy EA, Pyeritz RE. Progression of aortic dilatation and the benefit of long-term beta-adrenergic blockade in Marfan's syndrome. N Engl J Med 1994; 330(19):1335-1341. doi:10.1056/NEJM199405123301902

29. Chiu HH, Wu MH, Wang JK, et al. Losartan added to B-blockade therapy for aortic root dilation in Marfan syndrome: a randomized, open-label pilot study. Mayo Clin Proc 2013; 88(3):271-276. doi:10.1016/j.mayocp.2012.11.005

30. Ahimastos AA, Aggarwal A, D'Orsa KM, et al. Effect of perindopril on large artery stiffness and aortic root diameter in patients with Marfan syndrome: a randomized controlled trial [retracted in: JAMA. 2015 Dec 22-29;314(24):2692-2693]. JAMA 2007; 298(13):1539-1547. doi:10.1001/jama.298.13.1539

31. Diehm N, Becker G, Katzen B, Benenati J, Kovacs M, Dick F. Statins are associated with decreased mortality in abdominal, but not in thoracic aortic aneurysm patients undergoing endovascular repair: propensity score-adjusted analysis. Vasa 2008; 37(3):241-249. doi:10.1024/0301-1526.37.3.241

32. Cheng D, Martin J, Shennib H, et al. Endovascular aortic repair versus open surgical repair for descending thoracic aortic disease a systematic review and meta-analysis of comparative studies. J Am Coll Cardiol 2010; 55(10):986-1001. doi:10.1016/j.jacc.2009.11.047

33. Harky A, Kai Chan JS, Ming Wong CH, Bashir M. Open versus endovascular repair of descending thoracic aortic aneurysm disease: a systematic review and meta-analysis. Ann Vasc Surg 2019; 54:304-315. e5. doi:10.1016/j.avsg.2018.05.043

34. Pasternak B, Inghammar M, Svanström H. Fluoroquinolone use and risk of aortic aneurysm and dissection: nationwide cohort study. BMJ 2018; 360:k678. doi:10.1136/bmj.k678

35. Baumgartner $H$, Bonhoeffer P, De Groot NM, et al. ESC guidelines for the management of grown-up congenital heart disease (new version 2010). Eur Heart J 2010; 31(23):2915-2957. doi:10.1093/eurheartj/ehq249

Address: Tom Kai Ming Wang, MD, Section of Cardiovascular Imaging J1-5, Heart, Vascular, and Thoracic Institute, Cleveland Clinic, 9500 Euclid Avenue, Cleveland, OH 44195; wangt2@ccf.org

\section{Changed your address? Not receiving your copies?}

To receive Cleveland Clinic Journal of Medicine, make sure the American Medical Association has your current information. Cleveland Clinic Journal of Medicine uses the AMA database of physician names and addresses to determine its circulation. All physicians are included in the AMA database, not just members of the AMA.

Only YOU can update your data with the AMA.

If your address has changed, send the new information to the AMA. If you send the update by mail, enclose a recent mailing label. Changing your address with the AMA will redirect all of your medically related mailings to the new location.

Be sure the AMA has your current primary specialty and type of practice. This information determines who receives Cleveland Clinic Journal of Medicine.

If you ever notified the AMA that you did not want to receive mail, you will not receive Cleveland Clinic Journal of Medicine. If you wish to reverse that decision, simply notify the AMA, and you will again receive all AMA mailings.

Please allow 6 to 8 weeks for changes to take effect.

\section{To contact the American Medical Association:}

PHONE 800-621-8335

FAX 312-464-4880

E-MAIL dpprodjira@ama-assn.org

US MAIL

Send a recent mailing label along with

new information to:

American Medical Association

AMA Plaza

Data Verification Unit

330 N. Wabash Ave., Suite 39300

Chicago, IL 60611-5885 